\title{
OPINIÓN
}

\section{¿Es necesaria una bioética infectológica?}

\author{
WALTER LEDERMANN D. ${ }^{1}$
}

IS IT NECESSARY AN INFECTIOUS DISEASES BIOETHICS?

\begin{abstract}
From the proposal of "bioethics" by VR Potter on 1970, we have attended to a true explosion in this field, with a final focus on investigation involving human beings and on the limits of the heroic measures for terminal or dying patients. More than one branch of medicine, like oncology and organ transplantation, has developed its own bioethical rules. Has come the time for infectious diseases? In our speciality, problems arise about the rationality of diagnostic procedures, the antimicrobial therapy and the politics on immunization. In therapeutics, the omission of some wide spectrum antibiotics on the basis of ecological and economics reasons, may require an informed consent, with all the restrictions that such a consent has, meanwhile on the field of immunization, the imposition of controversial vaccines could be a transgression of individual autonomy and the high cost of those not included in state programs constitute an unacceptable inequity. The multiple dilemmas in infectious diseases, however, can be resolved without a code of rules, but the help of ethical committees could be useful in the most troublesome cases.
\end{abstract}

Key words: Bioethics, Infectious diseases, Investigation, Antibiotics, Immunization.

El 6 de septiembre del año pasado falleció Van Rensselaer Potter, Profesor Emérito de Oncología de la Universidad de Wisconsin, quien en 1970, a través de un artículo publicado en Perspectives in Biology and Medicine, propuso un término revolucionario, hoy ampliamente usado: bioética. ${ }^{1}$ En dicho artículo decía: Una ciencia de supervivencia debe ser más que ciencia sola, y de esta manera propongo el término "bioética", en orden de enfatizar los dos ingredientes más importantes para alcanzar la nueva sabiduría, que tan desesperadamente se necesita: conocimiento biológico y valores humanos.
El profesor Potter siguió un largo camino de especialización "en embudo" hacia lo minúsculo, para abrirse luego hacia la amplitud: $\mathrm{Co}$ mencé -dice- como un químico, luego escogí la bioquímica, entonces la bioquímica del cáncer, después la bioquímica de una clase de cáncer, y en el presente estoy interesado en aspectos especiales de esa bioquímica. Sólo recientemente, en los últimos diez años, es que he tenido el tiempo de mirar a mi alrededor. ${ }^{2}$ Pues bien, hagamos un alto, entre las vacunas conjugadas y los carbapenems, para mirar a nuestro alrededor. ¿Qué vemos? Una verdadera explosión de la ética médica, ámbito al que

\footnotetext{
1 Unidad de Infecciosos y Segunda Infancia, Hospital Luis Calvo Mackenna.
} 
parece haberse reducido la inicialmente amplísima bioética de Potter, detonación traducida en cursos, congresos, publicaciones, comités y en el parto de algunos escasos expertos, si alguien puede verdaderamente llamarse así en materia tan sutil y densa a la vez.

Tratando de despejar esta explosión, una vez retirados los escombros y apartadas las esquirlas, podemos ver que la bioética actual se centra en dos campos principales: los límites en la investigación en humanos y las medidas extraordinarias en la mantención de la vida. Prueba de ello es la existencia en algunos hospitales de dos comités de ética, uno para cada campo. Pues bien... ¿habrá llegado el momento para las "éticas" de especialidades? ¿Están, por ejemplo, dadas las condiciones para una ética de la infectología - la infeccética - así como en un momento nacieron una ética de la oncología y una ética del trasplante de órganos?

Por cierto que este último es un campo más dramático, donde el fracaso desmoraliza y el sufrimiento de los pacientes es largo, de manera que los problemas éticos adquieren un especial relieve. En un texto recientemente publicado, Veatch puntualiza lógica y secuencialmente los tres tópicos mayores en la ética del trasplante: la definición de muerte, el procuramiento de órganos y la asignación de éstos. ${ }^{3} \mathrm{Y}$ agrega que los tres están influenciados por dos grandes visiones sobre el procedimiento en sí: un rango amplísimo de perspectivas religiosas y culturales y esquemas éticos seculares para abordar las interrogantes que plantea. La definición de muerte parece ser un tema de infinita discusión, más filosófica que médica, en tanto que la manera de obtener los órganos, por donación voluntaria o supuesta, es el punto clave, pues puede no respetar plenamente el principio de autonomía, tanto que, para niños y animales, Veatch usa el término "fuentes" en lugar de donantes, dada su incapacidad para dar un consentimiento informado, que los convierte en donantes pasivos.

¿Tiene la infectología tópicos mayores tan claros? Probablemente, pudiendo agruparse en dilemas en el diagnóstico, en la terapéutica y en la prevención. Los infectólogos parecen haberse ocupado de ellos en orden inverso, constituyendo las inmunizaciones el punto más conflic- tivo, con problemas tales como la obligatoriedad de algunas campañas, la asignación de recursos y la elaboración de prioridades. Discutiendo sobre la vacuna varicela en reunión clínica, el chairman me hizo notar los reparos éticos que tendría una vacunación selectiva entre los sectores socio-económicos altos, que podrían costearla, en desmedro de los sectores pobres, que no tendrían acceso a ella. Infinidad de inequidades me vinieron de golpe a la mente, trasladando un problema médico a un vastísimo campo político, filosófico y social, y convirtiéndolo así en un puzzle insoluble, pero dejándome en claro la existencia de una ética de inmunizaciones.

Un par de años atrás, la introducción de la vacuna hepatitis A en Chile generó controversias, argumentando algunos de nosotros que su aplicación programática pudiera trasladar el problema hacia los adolescentes y adultos del futuro, quienes, vacunados en la infancia, perderían su inmunidad con el correr de los años y enfrentarían entonces una hepatitis quizás más severa. ${ }^{4}$ La cuestión estribaba en la legitimidad de privar de esta defensa a los niños de entonces por posibles amenazas a los jóvenes del mañana, con todo lo impredecible e hipotético que es el futuro, dilema que mezclaba elementos médicos, éticos y filosóficos. Y no olvidemos los aspectos legales, pues una acusación de mala práctica podría afectar, y con sólido fundamento, al pediatra que hubiera omitido una vacuna, efectiva y disponible en el mercado, en un paciente luego agobiado por una hepatitis fulminante.

Mientras se argumenta acerca de la inequidad que representa la posibilidad de usufructuar de las ventajas de inmunizaciones más amplias en los sectores adinerados, nadie parece reparar en que la obligatoriedad de algunas vacunas representa una imposición también carente de equidad. La prevalencia de la tuberculosis en los sectores más pobres de la sociedad, llevó en algún momento a introducir la vacunación BCG al nacer. Nunca he sabido que se pregunte a los padres de los niños nacidos en las clínicas privadas preferidas por el estrato económico alto, para quienes el contacto TBC es una amenaza remota, si están de acuerdo en inocular a su hijo recién nacido con una vacuna resistida en los 
países desarrollados, algunos de los cuales la han abandonado sin mayores consecuencias, ${ }^{5} \mathrm{y}$ cuya historia ha sido dramática, controversial y discutible desde los tiempos de Calmette y Guérin. ${ }^{6}$

Si aceptamos una ética para las inmunizaciones, podemos seguir con los antibióticos. En el nosocomio que me cobija tenemos normas de antibióticos que cautelan su buen uso, cuidando por una parte de no generar resistencia entre las bacterias enemigas y, por otra, de no recargar un presupuesto de farmacia siempre insuficiente para nuestra voracidad terapéutica. Así, los pacientes oncológicos afectados por neutropenia febril, se someten a un esquema empírico de cefotaxima más cloxacilina, mantenido en el tiempo, a pesar de la creciente resistencia del Staphylococcus aureus, que ha llegado por momentos a rondar el $40 \%$ en las cepas aisladas de infecciones nosocomiales: en esta situación, estamos encubriendo nuestro legítimo deseo de no recargar el presupuesto al comprar vancomicina, argumentando que deseamos evitar la selección de mutantes resistentes, implícita en el uso y abuso de este glicopéptido... ¿Problema bacteriológico o económico? Quizás ambas cosas, pero también dilema ético.

El párrafo anterior me lleva a analizar la dualidad de nuestro accionar, como médicos institucionales, con énfasis en la salud pública, y médicos privados, con énfasis en la salud del cliente. En este último papel, nos adaptamos a la antigua relación médico-paciente, en que la racionalización de los recursos no nos preocupa mayormente, la ecología microbiana no existe y el bienestar de la comunidad se aleja de nuestra mente, envuelto en una vaga nebulosa donde la responsabilidad social se diluye. Dentro del hospital, en cambio, nuestra mentalidad se abre a un sistema ético que considera como el más preciado bien la salud de la comunidad, con la imperiosa necesidad de racionalizar los recursos. Comportarnos de igual manera en el hospital y en la consulta, con la misma responsabilidad social, requeriría para cada uno de nosotros una profunda introspección y más de alguna renuncia. Como bien dice Albert Tauber, los médicos, como todos los ciudadanos, tienen una doble identidad, comunal y privada, cada una atendiendo diversos roles asociados y cumpliendo diversas obligaciones. ${ }^{7}$
Siempre en el campo antimicrobiano, deberíamos quizás plantearnos si estamos respetando el principio de autonomía del paciente con estas decisiones terapéuticas, que no son menores. Así como los cirujanos lo solicitan para todas sus intervenciones... ¿debiéramos pedir consentimiento informado al momento de elegir un esquema teóricamente "inferior"? ¿No sería necesario explicar al paciente que vamos a emplear cloxacilina, existiendo un porcentaje alto de resistencia a este antibiótico, con los loables fines de ahorrar dinero para otros pacientes, de no causar daño ecológico con un aumento de la resistencia y de mantener vigente este antimicrobiano en beneficio de todos?

Por desgracia, el consentimiento informado es un procedimiento imperfecto, merecedor de serios reparos. Primero, para ejercer su autonomía, el paciente no debe estar menoscabado en su capacidad de juicio. Desafortunadamente, las decisiones médicas más graves afectan a pacientes debilitados, quienes tienden a ser dependientes y pasivos ${ }^{8}$ y no están en condiciones de decisión activa; por otra parte, el médico, una figura autoritaria, presenta el consentimiento como única alternativa lógica, en un lenguaje médico que no puede sino resultar confuso y hasta intimidante para el lego. ${ }^{9}$ Así "informado", concluye Waller, el paciente termina por acceder pasivamente. ${ }^{10}$ En suma, el paciente acepta tanto su destino como reconoce la supremacía en conocimientos del médico tratante. Wallston ${ }^{11}$ sostiene la utilidad de permitir a los pacientes participar en el mayor número posible de decisiones terapéuticas, pues así se logra una mayor adhesión al tratamiento y una mejor tolerancia del mismo.

No es un problema menor la pasividad de nuestros pacientes, a la que suele unirse la desesperanza que se apodera de quien sufre patología oncológica, pues estos efectos espirituales o psicológicos no sólo perturban su capacidad de libre elección: tienen también una significativa acción sobre el sistema inmune, haciéndolos más vulnerables a las infecciones oportunistas, mientras que la capacidad de tomar decisiones activas, de sentir que se tiene el control, resulta indudablemente beneficiosa. ${ }^{12}$ Hace ya más de veinte años Ader propuso toda una subespecialidad de la psico-neuro-inmunología, ${ }^{13,14}$ que merece la mayor atención. 
De este modo, si quisiéramos considerar su autonomía, fortaleciendo su capacidad de tomar decisiones y activando de paso su sistema inmune, debiéramos preguntar a nuestros neutropénicos febriles (o a sus padres, en pediatría), luego de un consentimiento muy bien informado, si desean correr el riesgo de recibir cloxacilina, con alta probabilidad de fracaso, a cambio del beneficio de otros futuros e hipotéticos pacientes, o recibir vancomicina, con mejores posibilidades inmediatas, pero con perjuicio a largo plazo para la comunidad. ¿Así informados, cuántos tendrían la grandeza de alma para preferir la cloxacilina y cuántos el valor para resistir a la autoridad que el médico veladamente está ejerciendo en favor de este antimicrobiano?

Contando ya con una ética de inmunizaciones y una ética de antimicrobianos, abordemos la ética de los exámenes de laboratorio. Con ánimo docente, instamos a alumnos y colegas a omitir muchos de ellos, con una visión económica, pontificando sobre la bondad de la "clínica". La duda es si esta "clínica" sigue siendo la medicina al lado del enfermo, escuchando y atesorando sus síntomas, como preconizaban maestros de la talla de Sir William Osler, cuya supervivencia se ha puesto en tela de juicio, ${ }^{15} \mathrm{O}$ si, en su defecto, hoy debemos entender como clínica la justa evaluación de los análisis de laboratorio, de las imágenes y de las pruebas funcionales. Discutiendo con mi respetado maestro sobre el tamaño de un bazo, lo ofendí severamente al proponerle una ecografía que nos arrojaría una medición exacta. ¿Estaba ese procedimiento demás? Quizás, pero no está de sobra pedir serología para el rasguño de gato en un síndrome febril prolongado, aunque la clínica nos diga que es una etiología improbable: no escondamos tras nuestra supuesta sapiencia clínica, basada tal vez en pura vanidad, el legítimo deseo de abaratar costos. Y tenemos así otra rama de la infeccética.

Si seguimos hurgando en las actividades médicas que cumplimos a diario, iremos encontrando nuevas instancias éticas, no porque la infectología sea una rama médica muy particular, sino porque la ética está presente en todas las decisiones de nuestra vida. Está en nuestra conciencia y, salvo en las novelas y en el campo de la patología psiquiátrica, no existe el médico sin ella. Por grande que pueda ser el cinismo de alguna oveja descarriada del gremio médico, todos tenemos al menos un mínimo de conciencia moral, formada a lo largo de nuestro desarrollo cognitivo, que nos dice que está bien y qué está mal. Cuando el límite entre el bien y el mal se difumina por la complejidad del problema y por la gravedad de la decisión, se hace necesario el acopio de pareceres emanado de un comité consultor, el cual requiere, para funcionar bien, no de leyes escritas, sino de buen juicio y de buena fe. No hagamos un código de ética infectológica, que nos llevaría fatalmente a un enfrentamiento más burocrático que racional de los dilemas, y centremos los esfuerzos en buscar la perfección en nuestro diario accionar. La ética es una sola; la bioética, un término convencional, cuyo fraccionamiento por especialidades sólo engrosaría los diccionarios, sin mejorar necesariamente las conductas. En otras palabras, si existe una ética de la infectología, no necesita de un nombre para ejercitarse.

\section{RESUMEN}

Desde que VR Potter propusiera el término "bioética" en 1970, hemos asistido a una verdadera explosión en este campo, constituyendo sus temas principales la investigación en humanos y las medidas extremas para conservar la vida. Algunas ramas de la medicina, como la oncología y el trasplante de órganos, han establecido sus propios códigos. ¿Ha llegado el momento para la Infectología? En nuestra especialidad los problemas éticos se presentan en la racionalización de procedimientos diagnósticos, terapia antimicrobiana y programas de inmunizaciones. La omisión de antimicrobianos de amplio espectro por consideraciones ecológicas y económicas, quizás requeriría de un consentimiento informado del paciente, con todas sus limitaciones, en tanto que la imposición de determinadas vacunas puede lesionar la autonomía individual, mientras el alto precio de aquéllas no incluidas en programas estatales constituir una inequidad inaceptable.

Los numerosos dilemas éticos en infectología, sin embargo, pueden resolverse sin necesidad de códigos escritos, aun cuando la asesoría de un comité pudiera ayudar en los casos más delicados. 


\section{BIBLIOGRAFÍA}

1.- POTTER V R. Bioethics: The science of survival. Perspect Biol Med 1970; 14: 127-53.

2.- POTTER V R. Bioethics: Bridge to the future. Prentice Hall, N. York, 1971.

3.- VEATCH R M. Transplantation ethics. Georgetown Univ Press, Washington D.C., 2000.

4.- SOCIEDAD CHILENA DE INFECTOLOGÍA. Comité Consultivo de Inmunizaciones. Consideraciones sobre el uso programático de vacuna inactivada contra la hepatitis A en Chile. Rev Chil Infect 1999; 16: 315-20.

5.- SÁNCHEZ-ALBISUA I, BAQUERO-ARTIGAO F, DEL CASTILLO F D et al. Twenty years of pulmonary tuberculosis in children: what has changed? Pediatr Infect Dis J 2002; 21 (1): 49-53.

6.- LEDERMANN W. La tuberculosis después del descubrimiento de Koch. Rev Chil Infect 1997; 14: 196-200.

7.- TAUBER A I. Medicine, public health and ethics of rationing. Perspec Biol Med 2002; 45: 16-30.
8.- LIDZ C W, APPELBAUM P S, MEISEL A. Two models of implementing informed consent. Arch Intern Med 1988; 148: 1385-89.

9.- PRESS Y. The predisposition to file claims: The patient's perspective. Law Med Health Care 1984; 12: 53-62.

10.- WALLER B N. Patient autonomy naturalized. Perspect Biol Med 2001; 44: 584-93.

11.- WALLSTON K A. Psychological control and its impact in the management of rheumatological disorders. Bailliere's Clin Rheumatol 1993; 7: 28195.

12.- WIEDENFIELD S A. Impact of perceived selfefficacy in coping with stressors on components of the immune system. J Pers Soc Psychol 1990; 59: 1082-94

13.- ADER R. Psychoneuroimmunology. Academic Press, N. York, 1981.

14.- ADER R. Developmental psychoneuroimmunology. Dev Psychobiology 1983; 16: 251-67.

15.- BARONDES J. Is Osler dead? Perspect Biol Med 2001; 45: 65-84.

Correspondencia a:

Walter Ledermann Dehnhardt

Email: nmayor1@ hotmail.com 